\title{
Study on Effect of Comfort of Composite Tube Truss Floor in Different Sizes of the Concrete Slab Xin $\mathrm{HAN}^{1, a,{ }^{*},}$, Yi WANG ${ }^{2}$, Xue-Li ZHAO ${ }^{3}$ \\ ${ }^{1,2,3}$ School of Civil Engineering, Chang'an University, No.161 Chang'an Road, Xi'an, Shan Xi province, 710064 , China \\ a286695927@qq.com \\ ${ }^{*}$ Corresponding author
}

Keywords: Composite Tube Truss Floor, Comfort, Concrete Size.

\begin{abstract}
Along with the development of our country's economic and the improvement of science and technology, more and more sleek, novel structure of multilayer large-span spational structure has been developed rapidly. At present, the study for the new composite tubular truss floor is few in our country. However, under the walking, running and other normal activities, these large-span floor structure is easy to be excited vibration and even resonance, which will cause discomfort and panic for people. Therefore, here with the basis of the composite tube truss floor structure as the research object, studied the effect of concrete slab of composite tube truss floor comfort.
\end{abstract}

\section{Introduction}

With the development of economy and the improvement of construction technical level, domestic and foreign high-level, high-rise and large span a variety of complex space structure buildings are on the rise, such as the airport, stadium, multi functional hall, exhibition hall and other public buildings. Composite tube truss floor has extensive application value in the large-span space structures, so there is the very important meaning to study it. But the long span composite tube truss floor structure also has a problem that cannot be ignored--vibration comfort, this paper is put forward under this background the comfort of composite truss floor structure tube.

\section{Model establishment and analysis}

Concrete floor size is an important factor influencing the dynamic characteristics of composite floor slab size. The increase will bring the influence in two aspects, one is the increase of floor stiffness, but also increased the quality of floor system. In the SAP2000 finite element analysis of concrete slab as part of a mass source, change of concrete plate size of composite tube truss floor dynamic characteristics and vibration response of the impact cannot be ignored.

Restrict the other parameters of the structure analysis of invariant, $42 \mathrm{~m} \times 45 \mathrm{~m} \times 2.5 \mathrm{~m}$ and $42 \mathrm{~m} \times$ $63 \mathrm{~m} \times 3 \mathrm{~m}$ two floor under the form of plate size on the floor vibration effects. Combined with the actual engineering and related specifications, change value of concrete size is $120 \mathrm{~mm}, 150 \mathrm{~mm}$, $180 \mathrm{~mm}, 200 \mathrm{~mm}, 220 \mathrm{~mm}$. Figure. 1 shows that the change trend of the nature vibration frequency with concrete floor size. We can see that with the increase of the size of concrete slab floor structure, cycle longer, reduce the natural frequency, decreases in the range of about $19 \%$, by the analysis and comparison of the shows that the truss provides stiffness is much larger than the out of the plane slabs provide the stiffness, and the same stiffness of the truss rod weight is much smaller than the concrete slab weight, height of truss is increased floor natural frequency is increased. Therefore, from the control of nature vibration frequency of angle vibration comfort design, increase the concrete slab size on vibration comfort is not good.

Figure 2 and figure 3 gives the floor vibration response of a structure with the variation of the plate size. It can be seen, along with the increase of thick plate, vertical deflection of floor structure has a linear growth trend, according to the nature vibration frequency of the plate deflection calculation formula of floor system, the increase will reduce its nature vibration frequency, and this a rule of self 
vibration frequency changes with size coincided with peak acceleration; Response to the span of the structure due to the increase in the size of the floor slab, floor structure to improve pedestrian excitation resistance inertial force decreases, reducing the amplitude at about $13 \%$, compared with the vibration of truss floor response acceleration effect is relatively small truss height on the combined pipe. Further it indicated that the increase of concrete plate size does not significantly improve the overall floor stiffness of the system, at the same time, due to the large span of the structure, increasing the concrete size will substantially increase floor system weight, increase the vertical displacement of the causative structure.

Integrated the above analysis results, because adding concrete size to reduce the vibration of floor structure response effect is not obvious and the economy is not good.. In the composite tube truss floor structure design, it can be given priority by reasonable selection of truss height to improve the structure of the vertical flexural rigidity of the structure design, to meet the vibration comfort requirements.

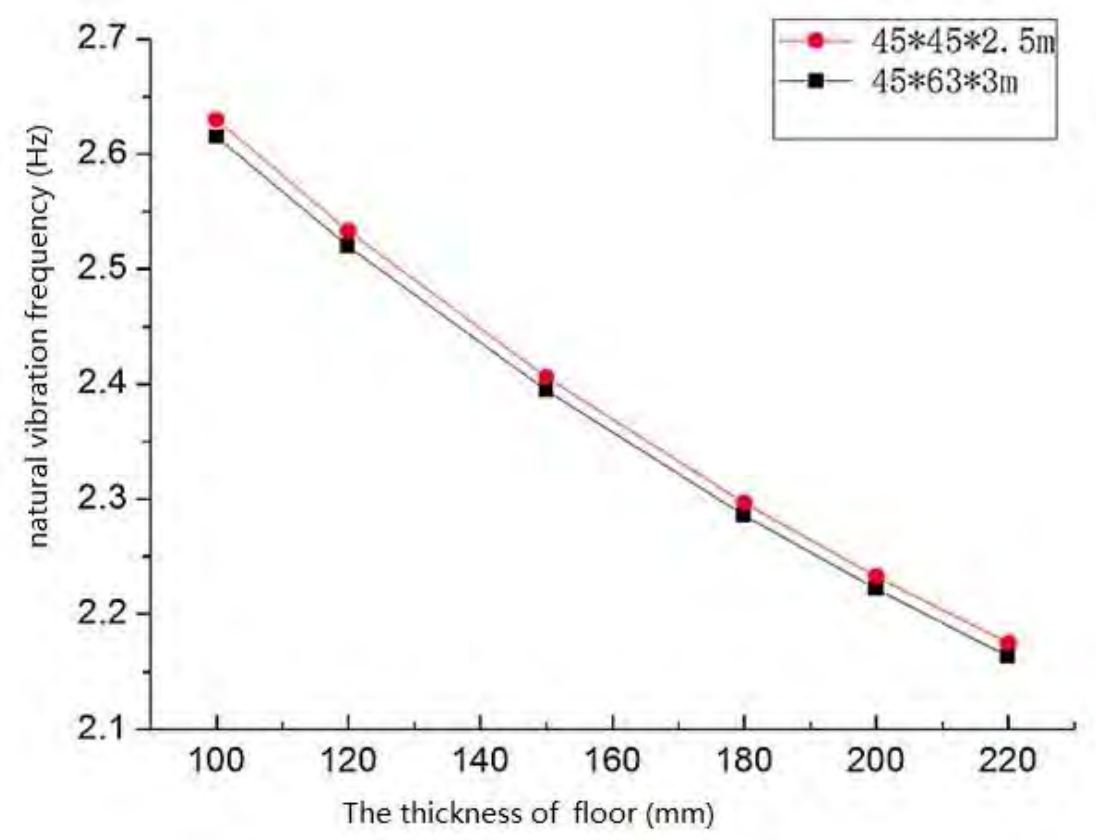

Fig. 1 Floorvibration Frequency Change with the Concrete Slab Size

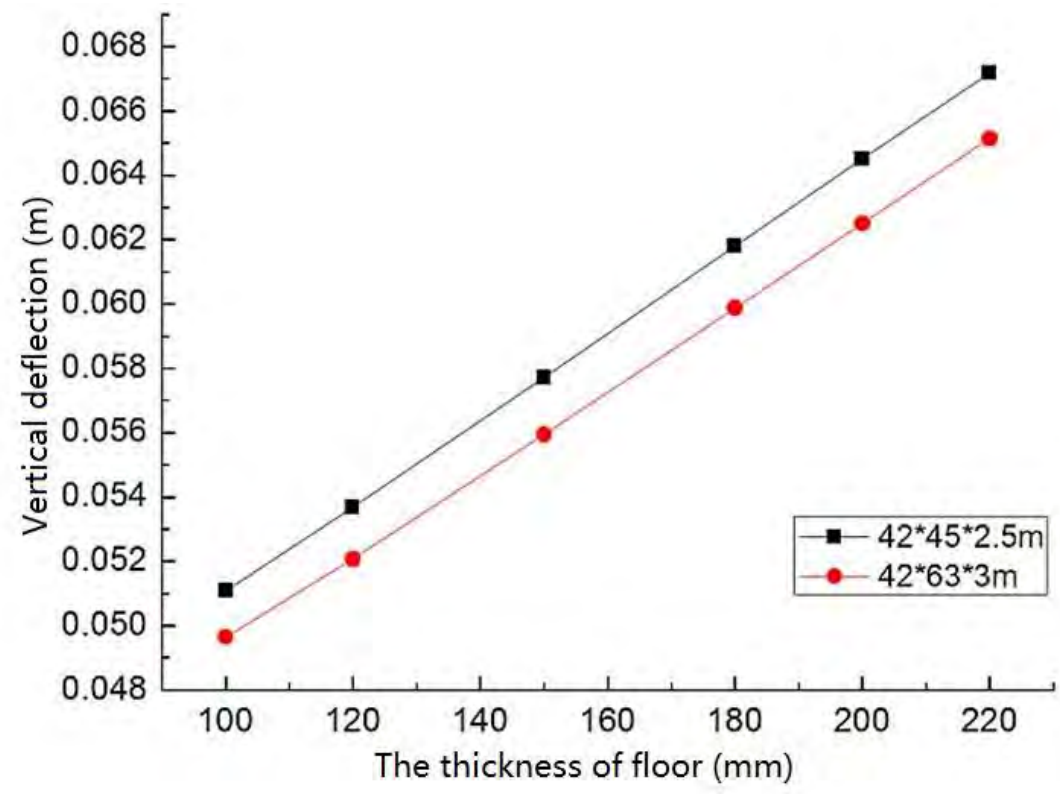

Fig. 2 Floor Vertical Deflection Change with the Concrete Slab Size 


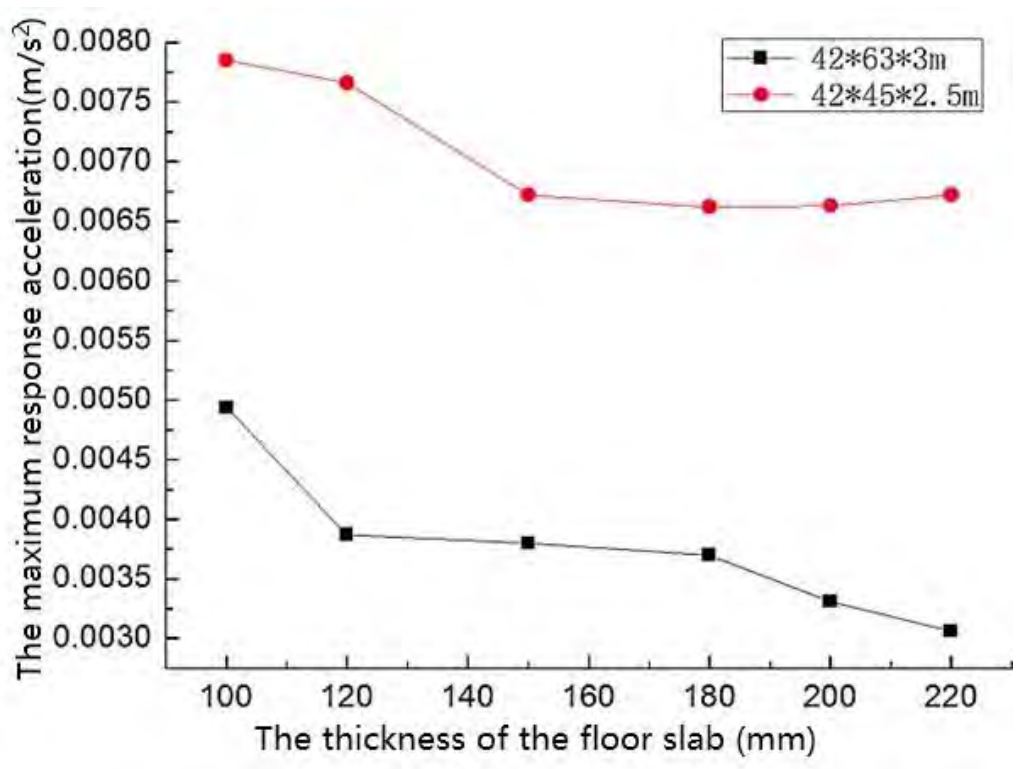

Fig. 3 The Acceleration Response Peak Value Varies with the Concrete Floor Size

\section{Conclusion}

This chapter takes the modelof composite tube truss floor this model as the research object, and analyzes the concrete roof plate size on the floor structure system vibration comfort of the impact, The main conclusions are the following:

(1)When concrete size change in $120 \mathrm{~mm}, 150 \mathrm{~mm}, 180 \mathrm{~mm}, 200 \mathrm{~mm}, 220 \mathrm{~mm}$, periodic floor structure of variable length, and the natural frequency reduce. From the facture of the control of nature vibration frequency to designn the vibration comfort, increase the concrete slab size on vibration comfort is bad;

(2)The vertical deflection of floor structure as the size increases show linearly increasing trend;

(3)Due to the size of the increment of resistance of inertial force floor structure of human walking, acceleration response peak in the span of the structure decreases, decreases in the range of about $13 \%$, compared with the vibration of truss floor acceleration response of the relatively small impact of truss height on the combined pipe;

(4)Increasing the concrete size to reduce the vibration of floor structure response effect is not obvious and the economy is not high.

\section{References}

[1]J. Yigang Zhang, Suduo Xue, Qingshan Yang. The large span spatial structures [M]. Beijing: Mechanical Industry Press, 2005: 7-25. (In Chinese)

[2]Ellingwood B., Taliin A. Structural Serviceability Floor Vibrations [J]. Journal of Structural Engineering, 1984, 110(2): 410-418.

[3] GB 50010-2010, code for design of concrete structures [S]. Beijing: Chinese Architecture Industry Press, 2010. (In Chinese)

[4]Thomas M., Joseph N., et al. Serviceability Lively Floors-North American and British Design Methods [J]. Construct Steel Res, 1998, 46(1-3): 105.

[5] Andriacchi T., Ogle J., Galante J. Walking Speed as a Basis for Normal and Abnormal gait Measurements [J]. Journal of Biomechanics, 1977, (10):261-268.

[6]Ohlsson S.V. Floor Vibration and Human Discomfort[D]. Goteborg,Sweden: Chalmers University of Technology, 1982. 
[7]ISO 2631:1974. Guide for the Evaluation of Human Exposure to Whole-body Vibration [S]. International Standard Organization,1974.

[8]Liu Zhenlin. The crowd load vibration influence on the station hall long-span floor analysis [D]. Beijing: Beijing Jiaotong University, 2012.

[9]Pachhi A., Ji T.. Frequency and velocity of people walking[J]. The Structrue Engineer, 2005, 83(3):36-40. 